\title{
남남 및 삼각협력에 대한 동향 및 정책 시사점
}

고 미 라 / KOKA 지역 1팀 대리

\section{I. 서론}

지금 세계는 경제위기에 직면해 있다. 세계경제가 어 려워지면 각 국가는 국외로 빠져니가는 통화에 민감해 지고 해외원조 또한 이런 경제위기에 예외일 수 없다. 단순히 경제위기 뿐 아니라 공여국의 정치상황, 사회 문화 등 수원국의 외적인 요인들은 지속적인 무상원조 흐름을 방해한다. 이에 따라 변동성이 큰 공여국 원조 를 보완하기 위해 개도국 간 상호 비교우위를 바탕으 로 자립기반 구축에 초점을 둔 남남협력이 주목을 받 고 있다. 특히 아세안, 유립연합 등 지역 통합 움직임 이 횔반한 요즘 국제사회는 지역 간 긴민한 협력체계 를 요구하고 있고 게도국들 간 상호 협력강화는 이와 함께 더욱 견고해질 것으로 예상된다.

이러한 흐름을 빈영하여 지난 2008년 10월 21 22 일 이틀간 남남및 삼각협력에 관한 아시아 태펑양
지역 개발협력포럼"이 태국 방콕에서 개최되었다. 이번 회의는 2010년 개최 예정인 개발협럭포럼 (DCF/ Development Cooperation Forum)의 아시하 지역 준비 모임으로 UNDESA(Department of Economic and Social Affairs), UN ESCAP (Economic \& Social Commission for Asia and the Pacific), UNDP SSC(South-South Cooperation)가 공동으로 주관하었으며 최근 이슈가 되고 있는 남남 및 삼각협력에 대한 (1) 경험 공유, (2) 모니터링 및 펑 가, (3) 정보 수집 및 분석, (4) UN의 역할 등 4 개의 세 션으로 나누어 찹가자들 간 논의가 진행되었다. 득히 이번 회의의 기조연선을 맡은 Nagesh Kumar 교수 는 남남 및 삼각협력에 대한 일반적인 흐름 및 특징들 을 정리하면서 이에 대한 확대 필요성을 강조하였다.

개도국에서 신흥공여국으로 전화된 한국은 2010년 $\mathrm{DAC}$ 가입을 앞두고 어느때 보다 이러한 기발원조 동

1) 인도 RIS (Reseach \& Irformat on Sys:em fo Deve oping Countries) 소속 교수 
항파악 및 동참이 필요한 시기이다. 따라서 Kumar 교 수의 발표내용- 및 $\mathrm{ECOSOC}$ 가 2008년 4월 발간한 “남 남 및 삼각협력에 대한 동향”을 바탕으로 남남 및 삼각 협력의 일반 개념 및 틎징을 징리하고 앞으로 적용방 인에 대해서 제안해 보고자 한다.

\section{II. 남남 및 삼각협력 동향}

\section{1. 남남협력이란? 삼각협력이란?}

공적개발 원조에 있어 South-South Cooperation에 대한 하나의 통일된 징의는 없지만 UNDP는 "개도국 간 성공시례 및 기술을 공유하고 배워 호과적인 게발 원조를 증진시키는 방식 중의 하나'로 정의하고 있 다. ("means of promoting effective development by learning and sharing best practices and technology among developing countries.") 아울리 일본 JICA는 남남협력을 "기술 경제협력 시, 개도국 간 관계강화 및 시속적인 자기개발을 목표로 하는 상 호협력"이라고 정의하며 일본 나름의 님남협력에 관 한 지침을 마련하고 있다(“mutual cooperation aimed at fostering self-sustaining development, involving deepening relations among developing countries while conducting technical and economic cooperation”). 이 두가지 정의의 공통점에서 보면 남 남헙력은 게도국 간 상호 기술협력 및 경험공유를 통 한 효과적인 개발원조 수행방식을 의미한다는 것을 알 수 있다.

아울러 남측 국기들의 노력에 더하여 부족한 재원 및 자원을 북측 국가들이 제공하는 삼각구도를 삼각협력 (Triangular Development Cooperation/TDC)이라고 부른다. 삼각협력은 참가국 구성에 따라 북-분남,

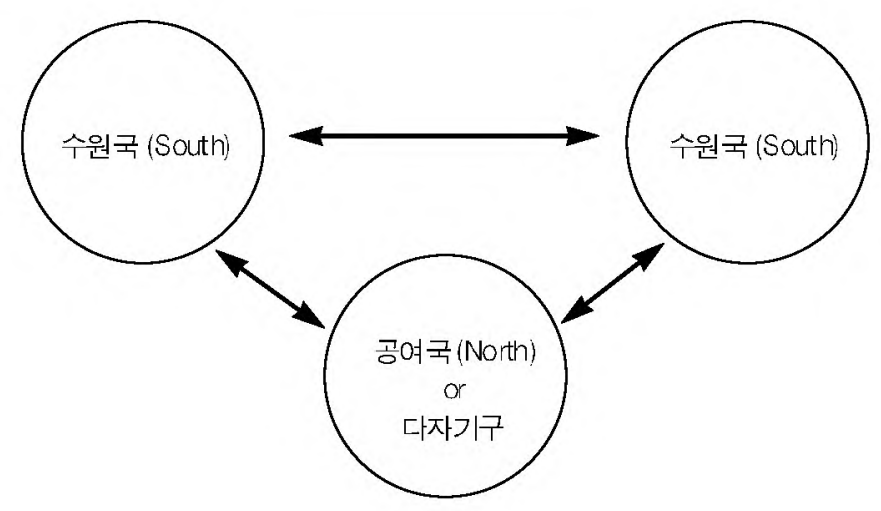


남-남-남이 될 수도 있겠지만 전자는 North-South 의 일반 형태로 분류될 수 있고 후자는 South-South 형태로 분류될 수 있기 때문에 일반적으로는 남-남북 증 남남협력을 보완하는 차원의 삼각형태를 삼각협 력으로 보-는 시각이 많다.

남남협력의 보족한 비분을 북측 국가 또는 다사 협력기 구가 보완하면서 시너지 효과를 창출하는 삲각협럭은 효과적인 빈곤감소 및 다양한 파트너들을 침가시키는 등의 긍정적인 요인이 많아 점차 확대되는 추세이다.

이번 회의에 GTZ 내표로 찬서한 James Tomeko, 재 무사업부 팀장은 현재 GTZ는 공식적으로 14 개의 프 로젝트가 삼각협력으로 진행 중이며 남측국기들의 비 교우위를 분야별로 분석하여 공동협 력 중임을 언급하
였다.

아울러 일본대표로 참석한 Jiro Usui, ESCAP 대표부 서기관은 아시아 지역내 개빌-경험을 아프리카로 전수 시키는 TICAD(Tokyo International Conference on African Development)에 대해 간략히 언급하면서 남 남협력 방식 등 가능한 모든 사원을 할용하여 $\mathrm{MDG}$ 달 성에 적극적으로 참여할 것이라고 언급하였다.

하지만 DAC 회원국들은 이를 양자협력과는 별도의 통 계 보고를 하고 있시 않아 느 방대한 규모를 정확히 측 정하는 것은 무리이녀 그 번위 및 형태가 다양하고 동 일된 방식이 없다. 따라서 〈Box 1)과 깉이 각 국가의 예시 밎 시례를 통해 삼각협력에 대한 이해를 돕고자 한다.

\section{〈Box 1〉 정부간 삼각협력 프로그램 예시}

\section{- NERICA 쌀 (New Rice for Africa)}

서아프리카 쌀 개반협회(WARDA)는 아프리카 쌀과 아시아쌀의 장점을 견합 시켜 1994년 새루-운 종자의 쌀을 개발하였다. 주요 협력 프로젝트로서, 일본, 중국, 아프리카 17 개국의 국가 기관들과 일본정부, UNDP, 아프 리카개발은행. FAO. USAID, 록펠러재단, 세계은행에 의해 지원이 실시뇌헜다. 네리카 쌀에 대한 수요 증가 로 인해 아프리카쌀 협회(A RI/ African RiceAssociation)가 설립되었으며, 농 협회는 서부, 중부 아프리카에 210.000 헥타르 이상의 농경지 구축과 170 만명의 아프리카 농부들에게 NERICA를 소개하며. 연간 744,000 톤까지 아프리카 쌀 생산량을 증가시켜 쌀 수입에 있어 연간 8800 만 달러의 질약을 모표로 한다.

\section{- 아시아대평양 장애개발센디 (APCD/ Asia Pacific Development Centre on Disability)} JICA와 태국 정부는 장애인들의 empower-ment 증진을 목표로 하는 지역 센터를 공동 설립하고, 아시 아지역 내 개도국에 있어 사회적 차별퇴치에 합의하였나. 2002 년에 설립된 동 센터는, 배국 뿐 아니라 CLMV(Cambodian, Laos, Myanmar. Vietnam) 국가로버터 몸이 불편한 참가자들을 반아들여 그들을 empower 시기기 위해 ICT, 거뮤니디 기반의 재활, 장애인 차별 금지 등을 위한 지도를 시작하였다. 


\section{- 캄보니아 지역개발 프로젝트}

이 프로섹트는 칻보디아 약 140 반명의 난빈의 생계를 지원하는 섯을 목표로 일련의 커마니티 개발 활동 을 통한 식량 생신과 수입증대 활동(income generating activities), 공공보긴과 기초교육 등을 지원한 다. 농산물의 싱산성 증대를 위해 1930 개의 농부 그룹과 12,000 명의 농부를 대상으로 한 교육을 지원 하였고 문제 해결을 위한 나크로 파이넌스 프로그램과 $\mathrm{NGO}$ 를 설립하였다. 이 프로젝트는 일본 국제협 력센터의 지원 아래. UNOPS. 인도네시아. 타이. 말레이시아. 필리핀 정부가 공동으로 참가한다.

Source : Kumar 교수 발표. 자류. (South-South \& Triangular Cooperation in Asia-Pacific)

\section{2. 남남 및 삼각협력의 흐름}

1960 1970년대에 개도국들은 식민지 시대에서 벗어 나 가난과 서개발의 성장 엔진으로 재정적, 기술적 상 호협력을 갈망하기 시작하였다. 틈히 77 그룹 및 South Commission의 탄생은 남남협력 강화를 위한 제도 및 무역협력 기반 구축에 영향을 미쳤다. 중국의 탄자니아-잠비아 철도 건설 사업은 그 시대의 대표적 인 남남협럭 사업으로 손꼽히고 있다.

1980 1990년대는 많은 개도국들이 재정위기를 겪음 과 동시에 GATT 및 우루과이 라운드 등 자유무역체계 를 통한 외부 강압이 높아시고 무역의 외적 간섭이 커 지면서 남남 헙럭이 어려움을 겪는 시기이다. 하지만 최근 자속적인 개발 노력으로 님측은 더이상 뒤쳐저 있는 그룹이 아닌 적극적으로 $\mathrm{MDG}$ 달성에 참가하는 중요한 역할자로서 부각되고 있다.

\section{3. 남남협력 규모}

$\mathrm{UN}$ 경제사회이사회(ECOSOC/Eonomic\&Social Council) 가 2008년 4월에 발간한 DCF(개발협력 포럼) 의 준비 자료에 따르면 2006년 전체 ODA 규모의 약 7.8 9.8\% 해당하는 95억 121억불 정도가 남측 공여 국들의 원조로 측정된다고 한다. 남측 주요 공여국은 중국, 인도, 베네수엘라, 한국 등이며 이 국가들은 $\mathrm{DAC}$ 에 가입하지 않은 신흥공여국으로서 최근의 남남 협력을 적극적으로 이끌이 나가고 있다는 것이다. 최 근 남측 공여국들의 이전 약속사항들이 구체화된다면, 남남 개발협력 규모는 2010 년까시 약 150 억불까시 증 가할 것으로 동보고서는 예측하고 있달.

틓히 님측 공여국 대부분이 현재 아시아 지역에 분포 하는데 이는 아시아 지역의 수십년간의 지속적인 경제 성장과도 연관된다. 한국, 대만, 홍콩, 중국, 싱가포르, 인도, 태구 등의 아시아 지여 신흥공여구들은 수십년

\footnotetext{
2) 동 수치는 중국, 인도, 한국, 베네수델라 등 실제 데이터 수집이 기능한 남측 공여국들에 근거히여 작성된 수치로 전체 규노에비에 과소평기된 수치라고 동 보고서는 언급하고 있다.

3) 중국의 아프리카 원조확대계획 밎 남아프리카 공화국이 GNN 0.2-0.5\%를 개발협력 프로그램으로의 지원 예정 등을 고려 시, 함후 남남협력에 대한 촣액 수치는 증가할 것으로 추산됨
} 


\section{〈Box 2〉 방글라데시 남남협력 예시}

- 소엑 대출, 인구정책, 지역개반과 같은 특정분야에 전문가를 보유한 방글라데시는 방글라데시 아카데미 와 지역 개발 아카데니, 공공행정언수센터 등의 전문가들을 개도국에 보내고 있음.

- 특히 그라닌 은행(Gram een Bank)은 인도네시아. 말레이시아. 네팔. 아프리카 국가들의 소액대출 프로 그램을 맡아 진행하면서 1996년 워싱턴에서 열린 소액대출 정상회담을 이끄는 역할을 하기도 함.

Source : UN-ESCAP(2002)

간 축적된 개발경험과 기술을 통해 남남협력에 적합한 시스텐을 만들어 나가고 있는 것이다. 아율러, ASEAN, SSARC 등과 깉은 경제협력을 위한 지역기 구들이 조직됨에 따라 아시아 지역내 경험공유 및 기 술헙력을 위한 다양한 장이 형성되견서 남남헙력에 대 한 지원이 확대되고 있다. 또한 신흥경제성장국 빤 만 아니라 방글라데시와 같은 최빈개도국들(Least Development Countries : LDCs)도 주변국들과 함께 기술협력에 대한 노력을 시작하고 있다.

\section{III. 남남 및 삼각협력의 장단점}

남남 및 삼각협력은 노동 집약적인 개도국 기술이 선 진국의 기술보다 산업환경이 유사한 다른 개도국에게 더 적합하고 열악한 인프라 환경에 상대적으로 쉽게 적용이 가능하다는 특징이 있다. 아울러 개도국 전문 가들은 다른 개도국과 유사한 지질, 기후 환경에 적합 한 기술과 전문성을 가시고 있기 때문에 남-북 개발 원조에 비해 자원 효율성이 높은 편이다. 틓히 개도국 의 저렴한 물가는 비용 효과적으로 전문 기술을 전파
시킬 수 있는 장점이 있어 개발파트너 확대 뿐 아니라 , 원조 효과성 향상에도 기인할 것으로 보인다. 하지만 남남 및 삼각협력에 대한 일관된 개념정립 및 가이드라인이 부재하여 수행체계는 물론 모니터링 및 평가 시스템이 아직 미흡하다. 모니터링 및 평가 (M\&E)에 대해 눈의한 이번 회의 두번째 세션에서도 밀레이시아, 스리랑카 등의 남측국가들이 M\&E 역량 강화를 위한 공여국 및 다자기구의 지원을 긴의하는 등 이에 대한 보완을 강조하였다. 아울러 다양한 이해 관계지들이 참가하게 되년서 상호 간 공감대 형성 및 이해가 선행되어야하고 남측 찬가자들의 적극적인 협 력 및 행정역량이 성공의 중요한 오소로 고려되어야 할 것이다.

이외에도 $\mathrm{ECOSOC}$ 에서 발간한 DCF 준비보고서를 바 탕으로 남남 및 삼각협력 방식에 대한 장단짐을 좀 더 정리해 보면 이래와 같다.

\section{1. 장점}

- 비용효과성 
- 경제 · 문화적 기발환경이 유사한 국가 간 협력을 퉁해 수원국 흡수 능력을 제고하고 사업 추진비 용을 절감함으로써 가용 사원 할용의 극대화가 가능

- 참가국의 지속적인 역량강화

- 남측 국가들이 적극적으로 개발협력에 참여함으 로써 개발 역량제고 및 노하-욱축적의 기회를 제 공할 수 있고 지속적인 발전의 기반 바련

- 개도국 주인의식 및 리더십제고

- 수원국 중심의 기술협력 사업을 통해 실질적으로 필요한 수원국 수요를 반영하고 사업에 참가함으 로써 주인의식 및 리더십 제고 가능

- 유연성 확보

- 외부 횐겅에 즉각적으로 반응할 수 있고 상대적 으로 신속한 자금 지원 등 유연성 확보

\section{2. 단점}

- 남측 참가자들의 역량 미흡

- 각 국에 버합하는 사업관리 능력 및 역량 부재 시, 표과적인 사업 수행이 어려움

- 남측 국가 대부분이 원즈통합기구(Coordinating Agency)가 부재하여 협력 추진을 위한 인프라 구 축이 부족함

- 참가자간 긴밀한 협력체계 구축

- 침가국간 업무분장 등 획신한 추진 매커니즘 부 재시, 중복비용 발생 등 불필요한 재원소모가 발 생하므로 긴밀한 헙력 체계 선행 밀요

- 모니터링 및 평가체계 미흡

- 모니터링 및 평가 체계가 갖추어 지지 읺아 투입
자원의 성과측정이불확실

- 강한 정치적 동기와의 연관성

- 각 국의 정치적 동기와 연관될 경웅 수원국 전체 개발 조징 및 조화와 무관하게 진행되는 경우 발생

\section{IV. 정책 시사점}

남측 공여국의 역할이 커지고 북측 국가들이 이에 대 한 시원을 강화하면서 남남 및 삼각헙력에 대한 엉역 은 앞으로 전차 확대될 것으로 기대된다. 하지만 남남 협력의 원조방식이 성공을 거두기 위해서는 짧은 시간 에 외형적인 형태만을 따라할 것이 아니라 한국만의 적용방안을 찾고 이에 대한 개선이 필요하다고 생각한 다. 따라서 남남 및 산각협럭에 내한 내부의 강 - 약전 과 외부의 기회 · 위협요인들을 정리하여 실행방안을 생각해보고자 한다.

\section{1. 강점}

- 개도국 $\rightarrow$ 신흥공여국 $\rightarrow$ 공여국으로의 오랜 발전 겅험 축적

- 짧은 시간에 개도국에서 신흥공여국으로 자리매 김한 한국의 경제발전 경험은 남측국가의 좋은 모범사례로 남남 및 삼각협력을 효과적으로 수행 할 수 있는 역량 보유

- 남남 협력이 확대되는 아시아지역 양자협력 기반 활용 가능

- 신흥공여국이 많은 아시아 지역은 님남 및 삼각 
협력이 확대되는 지역으로 지리적 근접성 및 문 화적 유사성을 바탕으로 한 양자협력 경험 활용

- 파리선언에 적극적인 참가를 통한 원조효과성 향상 에 기인 가능

- $\mathrm{DAC}$ 가입을 앞두고 파리선언 등에 적극적으로 동참하는 등 국제사회의 원조효과성 향상 노력에 하고 있는 한국은 원조조화와 조정을 고더한 남 남 및 삼각협럭 추진 가능

\section{2. 약점 (Weakness)}

- 삼각협력에 대한 다양한 시도 부재

- 소규모 기술협력 (연수사입)사업에 경험이 한정되 어 다양한 형태의 남남 및 삼각협력 시도 필요

- 가이드라인 및 추진방향 미흡

- 맞츰형 기본방향성 및 가이드라인이 비흡하여 전 사적인 추진 징책 부재

- 지속적인 협의 채녈 부재

- 참가국 간 역량개발 발굴을 위해서는 정기적이고 시속적인 소통 필요하나 이에 대한 통합적인 협 의채널이 부재

(침고) 인본의 경우 남남 및 삼각협력 추진을 위한 대륙별 회의를 게최 운영 중임.

\section{3. 기회}

- 아시아지역(일본) 주축의 남남협력 확대 흐름

- 아시아 개도국 및 신흥공여국이 주축이 되어 확대 됨에 따라 남남 및 삾갂협럭 추진을 위한 기회 확내 - 국제사회의 관심 및 지원 증가
- 기발협력 파트너 확대 및 원조효과성 제고를 위 한 방안으로 $\mathrm{DAC}$ 등 국제 사회의 관심 및 지원 점차 증가

-수원국의 적극적인 참가의지

- 파트너 국가로 침가해야하는 수원국들 또한 필오 성을 인지하고 공감대가 형성되는 추세

- 한국 경제발전 경험에 대한 개도국 수요 및 관심 중가

- 한국의 단시간 경제발전 경험에 내한 관십이 증 가하면서 남남 및 삼각협력에 대한 한국과의 협 력 증가

\section{4. 위협}

- 국제 사회의 일관된 가이드라인 및 데이터 부재

- 국제사회의 일관된 가이드라인 및 데이터의 부재 로 각 국의 이해가 상이함

- 남측 참가국의 역량 미흡

- 사업 추진에 있어 남측 참가자들이 부족한 역량 은 사업 세부 추진을 어렵 게 함.

- 남측 국가들의 시속적인 협력 및 역량구축이 없 으면 효과성은 높지 않을 것으로 판단됨

- 세부 협의를 위한 준비기간 필요

- 다양한 이해관계자들이 참가하기 때문에 남남 및 삼각협력의 성공을 위해서는 세부 협의를 위한 준비기간이 필요함

남남 및 삼각협력의 국제적 흐름이 대세라 할지라도 이에 대한 철저한 준비가 없다면 성공하기는 어려울 것이다. 따라서 상기의 내외적 SWOT 분석을 바탕으 로 다음의 직용방안들을 고려하여 향후 님남 및 삼각 
〈표 1〉 한국의 남남 및 삼각협력에 대한 SWOT 분석

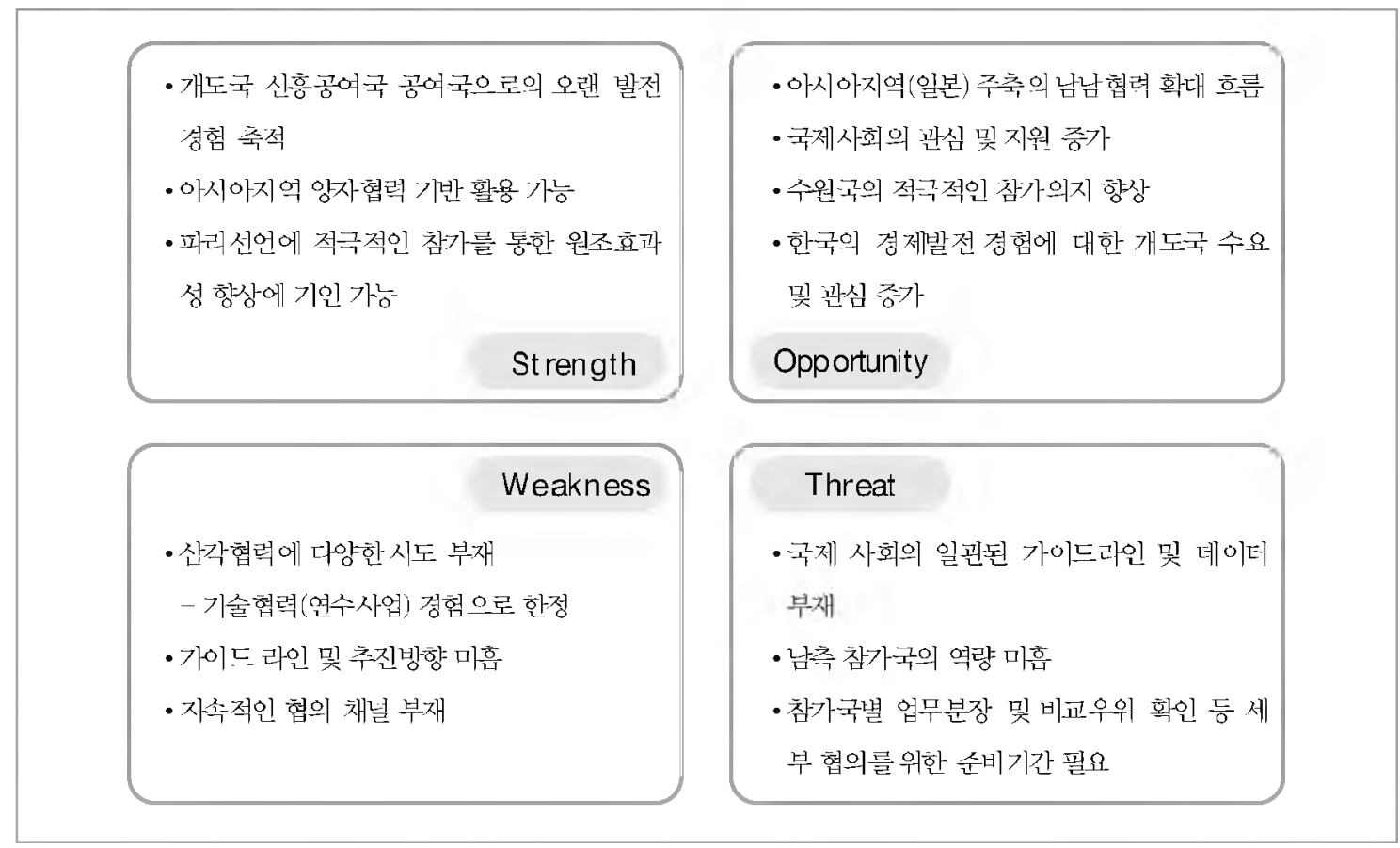

협력 추진에참고가 되었으면 한다.

\section{가. 고유 가이드라인 및 추진방향 수립}

한국의 부조한 부분을 보완하고 참가하는 님측 국가들 간 비교우위 확보가 성공의 중오 요소이므루 협력국 선정 기준 등 남남 및 삼각헙력을 위한 고유 가이드라 인 및 조진방향 수립

\section{나. 분업의 명시화}

남남 및 삼각협력은 다양한 주체들이 참가하게 되면서 사업 추진 중 증복성 문제 및 의견 대립 등이 발생하므
로 이를 최소화하기 위한 명확한 참가국 분업 선행

\section{다. 지속적인 협력 채널 유지}

짧은 시간에 헙려국 수요 및 비교우위 확인이 어려우 므로 지역별로 지속적인 대화 칭구를 마련하여 정기적 인 소퉁의 기회 마련

\section{V. 결론}

2008년 9월 아크라에서 열린 "원조효과 제고를 위한 고위급 회의"에서 개발 파트너 확내 및 포용을 위한 효 
과적인 원조 방식으로서 남남 및 삼각협력에 대한 이 슈가 논의되는 등 그 필요성이 점점 높아지고 있다. 하 지만 남남협력 규모 및 필요성 확대에 비해서 느간 체 계적인 가이드라인 및 정의가 없었고 따라서 이빈 방 콕 회의의 주제도 그러한 기본적인 프레임 구성에 대 한 요구가반영되었다고 볼 수있다.

이번 방콕회의에서 남남 및 삼각협럭에 대한 아시아 지역 내 높은 관심과 침가의지를 확인하였으며 공여국 은 물론 개도국 역시 새로운 원조방식 도입을 통한 협 력증진을 모색하었다. 아울러 이번회의는 남남협력에 대한 모니터링 및 평가 시스텐이 비흡하고 정보공유를
위한 제도가 부족하므로 이에 대한 UN기구의 억할 확 대가 필요하다는 공감대를 형성하면서 남남 및 삼각협 력에 대한 공동성명서(Joint Statment)를 채택하여 그 의미가 높았다.

이번 회의를 바탕으로 한국도 국제사회의 동향을 지속 적으로 관찰하고 난순히 형태를 모방하기보다는 참가 구 간 비교우위를 상호 보완하는 남남 및 삱각협럭이 필요할 것이라고 생각되었다. 따라서 고유의 가이드라 인을 수립하여 참여의지 및 역량이 높은 남측 파트너 국가들과 점차적으로 헙력을 확대해 나가야 할 것이라 고 생각한다.

\section{[ 첨 부 1 ] 아태지역 남남 및 삼각헙력 개발협력 포럼의 공동성명서 요야}

\section{$\mathrm{A}$ : FSCAP 지역 내 삼각협럭을 다 지역과 공유}

- 다수의 삼각협력 프로젝트를 기타 지역으로 확산 필요

- 민간분야 및 시민사회의 많은 관계사 참가사 유도

\section{$\mathrm{B}:$ 남남 및 삼각협럭에 관한 모니더링 및 평가 보완}

- 현재까지 모니터링 및 평가에 대한 정밀한 조사 부재

- 유연성 확보를 위해 국가주도의 효율적이고 포괄적인 M\&E가 필요하며 역량강화 프로그램이 선행 되어야함

$\mathrm{C}$ : 남남 및 삼각헙력에 관한 데이터 수집과 분식 필요

- 규모, 효율성, 질에 관한 지역적 분석작업이 없어 복잡해셔가는 협력방식의 통합적인 보고 밎 정보 수집이 부재함

- $\mathrm{OECD/DAC}$ 회원국들 대상으로 님남 및 삼각협력에 관한 별도 보고 시행 등 정보수집을 위한 양식 수립 검토 필요

\section{D: UN기구의 역할}

- 활발한 남남 및 삼각협력의 확대를 위해 UN의 적극적인 지지가 필요하며 UNDP SSC의 재정적, 기 술적 시원 획대 필요

- DCF가 남남협력에 관한 명확한 정의와 정확한 펑가법 기발 등 UN의 역할에 지속적으로 초점을 맞 추고 메커니즘을 조직화시켜야함 


\section{[ Reference ]}

UN ECOSOC `Background Study for the Development Cooperation Forum - Trends in South-South and Triangular Development Cooperation」/ April 2008

Dr. Nagesh Kumar 'South-South \& Triangular Cooperation in Asia-Pacific: Towards a new paradigm in development cooperation $\lrcorner$ 